\title{
EL DERECHO DE RECTIFICACIÓN Y SUS PECULIARIDADES CUANDO SE EJERCE POR LOS ACTORES DEL PROCESO ELECTORAL
}

\author{
MARÍA VICENTA GARCÍA SORIANO \\ Universidad de Valencia - Estudi General
}





\section{EL MARCO TEÓRICO DEL DERECHO DE RECTIFICACIÓN}

Estamos ante un derecho de procedencia francesa, basado en el droit de reponse que ostentaban los particulares ante informaciones que considerasen inexactas ${ }^{2}$. Constituye, para unos, una contrapartida del derecho de libertad de expresión y comunicación ${ }^{3}$; otros entienden que no afecta a la libertad de expresión, si acaso, incide sobre la libertad del periodista que dio la información ${ }^{4}$; incluso, se ha argüido que se trata de "uno de los límites al ejercicio del derecho de información».

2 En G. Burdeau, Libertes publiques, París, 1972, pueden encontrarse la diferencia entre el derecho de rectificación y el derecho de réplica que reside en la titularidad de los mismos: mientras el derecho de rectificación es aquel que pertenece a los poderes públicos, el derecho de réplica lo es de los particulares. El droit de reponse podia ejercerse cualquiera que fuese la naturaleza de la información noticia u opinión emitida, no siendo necesario que ésta fuera difamatoria, calumniosa o inexacta, sino que bastaba con que hubiese producido un perjuicio a su autor. Se trataba de un derecho general y absoluto cuyo titular debía tener un interés personal y directo sobre la información emitida. Se trataba de un derecho subjetivo: su titular es el único con capacidad para juzgar su ejercicio, su amplitud y su forma. Su ejercicio no debía ser contrario a las leyes ni atentar a los derechos e intereses de otras personas. Finalmente, BURDEAU indica que quien se negara injustificadamente a insertar la respuesta cometía un delito cuyo principal responsable era el Director del medio de comunicación afectado. Según la descripción que acabamos de reproducir el derecho de rectificación aquí tratado procederá del denominado droit de reponse.

Como podemos ver en el estudio que llevó a cabo T. González Ballesteros, El derecho de réplica y rectificación en prensa radio $y$ televisión, Madrid, 1981, págs. 28 , antes de la LO 2/1984, se diferenciaba entre replica y rectificación, siendo la actual rectificación lo que anteriormente se conocía como réplica.

Desde la LO 2/1984 se rompe la línea iniciada por el art. 25 del antiguo Estatuto sobre Radio y Televisión hoy abolido que establecía la distinción doctrinal antes referida. Al respecto resulta interesante la STC 146/1993 en que se refiere a la derogación de aquélla primera normativa específica por la actual LO 2/1984

La unificación de conceptos evita, por otra parte, las prerrogativas que antes tenía la Administración Pública en la Ley de Prensa e Imprenta de 18 de marzo de 1966, conocida como la Ley Fraga, colocando a la Administración en pie de igualdad junto a los ciudadanos. Así lo recoge R. MARTín Morales, El derecho fundamental al honor en la actividad política, Granada, 1994, pág. 133.

Finalmente, el Alto Tribunal, a propósito del ATC 49/1993, nos recuerda que "no existe base alguna en nuestro ordenamiento vigente para diferenciar entre derecho de réplica $y$ derecho de rectificación".

3 Está asumido el tópico de que "no hay derechos ilimitados», pero, como afirma la profesora SÁNCHEZ FERRIZ, el mismo no se puede aplicar de manera general a todos los derechos. Sin embargo en relación a la libertad de expresión resulta pertinente puesto que se trata de una libertad pública por excelencia. Ver su Estudio sobre las libertades, Valencia, 1995.

4 T. González Ballesteros, El derecho de réplica ..., op.cit. pág. 37 y ss.

5 S. RIPOLl CARULla, Las libertades de información y de comunicación en Europa, Madrid, 1995, pág. 89. También ve en el derecho de rectificación un límite a la 
Por nuestra parte nos situamos junto a los que creen que actúa, esencialmente, como garantía de la veracidad informativa ${ }^{6}$, teniendo en cuenta que ésta no se consigue tanto por la exigencia de la estricta coincidencia de la rectificación con la realidad de los hechos -la verdad del interesado puede ser absolutamente parcial- sino porque mediante "la difusión de informaciones contrapuestas"” se contribuye de manera indiscutible a descubrirla. En este sentido puede abordarse desde una doble perspectiva: como una de las garantías del derecho a la información en su vertiente pasiva, esencial en un Estado democrático y como garantía de la veracidad del objeto de ese derecho por constituir uno de sus límites internos y determinar -junto a otros factores- ${ }^{9}$ la extensión propia del mismo ${ }^{10}$. Así pues partimos de la consideración

libertad de prensa, especialmente al derecho a la información, M. CARRILLo, uLibertad de expresión y derecho de rectificación en la Constitución española de 1978 (Comentario a la LO 2/1984 de 26 de marzo)", en Revista de Derecho Político, núm.23, 1986, págs. 44 y ss.

Por su parte, el Tribunal Constitucional, desde la STC 6/1988 ha venido considerando la veracidad como un "limite interno de la libertad de información".

6 Asi lo calificó A. Fernández-MiRAnda y CAMPOAmOR, "Libertad de expresión y derecho a la información", en O. Alzaga Villaamil, Comentarios a las Leyes Políticas, Tomo II, 1984, pág. 532.

7 ATC 70/1992.

s Sobre la importancia de la información como determinante esencial de la actividad política en una democracia, ver R. SÁnChez FerRIz, Estudio sobre las libertades, Valencia, 1989, págs. 229 y ss. De la misma autora «El derecho a la información en la jurisprudencia del Tribunal Constitucional", en El derecho a la información, Cuadernos Lucas Mallada, núm.1, 1995, pág. 55, el derecho a la información se tiene de todo aquello que afecte a la convivencia política.

9 Sobre la conveniencia de analizar e interpretar los derechos desde su propio contenido o ámbito (delimitado en cada caso por diversos elementos o factores acordes con su naturaleza) ver, la opinión sobre las delimitaciones de R. SÁNCHEZ FErRIz, siguiendo a I. DE OtTo y L. Martí Retortillo, Derechos Fundamentales y Constitución, Madrid, 1978, en Estudio...op.cit.págs. 56 y ss.

10 Como sostiene M. Desantes Guanter y otros, Derecho a la información, II. Los mensajes informativos, Madrid, 1994, págs. 60 y ss., la información y la verdad son términos correlativos. La pureza de la noticia radica en que sólo la verdad permite ejercitar libremente el derecho a la información. Para el autor, tanto el error como la falsedad son relativamente remediables: por una parte con la autorectificación, por otra con la heterorectificación, se deba ésta, o no, al cumplimiento de las formalidades exigidas en la LO 2/1984.

Por otro lado, y tal como se plantea en la STC 41/1994 el problema se centraría en decidir si la veracidad se refiere a la efectiva existencia de, por ejemplo, unas declaraciones o cualquier otra manifestación de una realidad, o dicha exigencia debe extenderse también al contenido mismo de éstas. Esto es, si la diligencia exigible a Jos profesionales se extiende sólo a comprobar la certeza de que aquéllas se han realizado efectivamente, o si alcanzan a la comprobación de lo que se ha ma- 
La segunda es la posición que, a nuestro juicio, se acerca más a la doctrina del Tribunal Constitucional que ha considerado «el derecho de rectificación supone una garantía de la opinión pública libre, puesto que una versión disidente de los hechos publicados favorece, mas que perjudica, el interés colectivo en la búsqueda y recepción de la verdad que aquel derecho fundamental protege» ${ }^{21}$.

\section{CARACTERÍSTICAS}

Tiene como ha dicho en algunas ocasiones el Tribunal Constitucional ${ }^{22}$, un carácter instrumental en cuanto su finalidad se agota en la

del derecho de rectificación, por lo que, para que pueda llegar ante Tribunal Constitucional una controversia sobre el mismo, será preciso su conexión con alguno de los derechos de la Sección 1, del Capitulo II, Título I de la Constitución.

Las posibles vías serian: que el sujeto rectificante pudiese solicitar el amparo contra la negativa del medio -confirmada éste mediante sentencia judiciala difundir su rectificación, alegando que su actitud conculca alguno de los derechos fundamentales accionables en via de amparo; por otra, el medio de comunicación obligado por el Juez a publicar la rectificación podría solicitar del Alto Tribunal la anulación de la sentencia sobre la base de que vulnera su derecho a expresarse y comunicar información libremente, derecho, éste si, garantizado en el art. 20.1.d) CE.

c. Chinchilla Marin, «Sobre el derecho de rectificación (En torno a la Sentencia del Tribunal Constitucional 168/1986 de 22 de diciembre)" en Poder Judicial, núm.6, págs. 74 y ss.

21 STC 168/1986.Sin embargo, no podemos olvidar que está regulado mediante una Ley Orgánica, y éstas regularán, exclusivamente, los derechos fundamentales. Ver M. RAMIREZ, "Reconocimiento constitucional y vertiente sociopolítica», en El derecho a la información, Cuadernos Lucas Mallada, núm.1, 1995, pág. 31. En este sentido recuerda que hay una remisión que hace la Constitución a una ley posterior, que ha de tener un rango específico de ley orgánica, que, en relación al derecho del individuo a recibir información veraz, es la LO 2/1984.

22 STC 35/1983. Antes de la entrada en vigor de la LO ya el Tribunal habia establecido los principio básicos de este derecho. A saber:

a) Su ejercicio debe ser sumario de manera que, en lo posible, garantice la rápida publicación de la rectificación solicitada, pues, la demora de la misma podría impedir su finalidad.

b) Su ejercicio deberá ajustarse a los requisitos que, a su vez, ofrezcan al medio difusor de la información una garantía razonable de que la rectificación que se pretende se apoya en elementos de juicio que, de algún modo, invaliden la que se hizo pública. Ello es así porque está destinada a impedir un daño que, de otra manera, sufriría el derecho o el interés legítimo de quien la solicita, pues el derecho a la información o a la libertad de expresión no implica la difusión de noticias de dudosa veracidad o de las que se pueda seguir un perjuicio a la esfera jurídicamente protegida de terceros. 
rectificación de informaciones difundidas por los medios de comunicación consideradas lesivas de derechos propios de aquél que solicita la rectificación. Son datos que la persona aludida considera, subjetivamente, inexactos ${ }^{23}$ o inexistentes sin que sea relevante si se han publicado por error, por precipitación o malintencionadamente.

Sólo afecta a la difusión de acontecimientos experimentalmente demostrables (pero también cuando se informa de juicios de valor atribuidos a terceras personas) y no a la manifestación de opiniones, cuya responsabilidad asume quien las difunde ${ }^{24}$. Es, en consecuencia, un instrumento que se pone a disposición del particular para difundir un mensaje propio, relativo a unos hechos que le afectan, $y$ que va destinado a la colectividad ${ }^{25}$.

Sirve para prevenir o evitar el perjuicio que una determinada información pueda irrogar en el honor o en cualesquiera otros derechos o intereses legítimos del sujeto afectado quien, insistimos, sólo podrá ejercitarlo si considera que los hechos lesivos mencionados no son

c) Consecuencia de lo anterior resulta que, quien pretenda rectificar una información, tendrá que aportar la documentación en que se apoye la rectificación solicitada, y deberá, asimismo, precisar el texto de la rectificación.

${ }_{23}$ Sin embargo en el ATC 70/1992 se aclara que el derecho de rectificación «no subordina el derecho del rectificante a que éste acredite la veracidad de su versión de los hechos sino que, conforme al art. 1 de la citada Lev, basta que considere inexactos los hechos que le aluden y cuya divulgación pueda causarle perjuicion.

${ }^{24}$ En este sentido STC 35/1983.También, entre otras, las SSTC 168/1986, $6 / 1988$ y 51/1989. En la STC 168/1986 se dice: «La inserción de la réplica sólo procede en la medida en que se pretenden rectificar hechos y no opiniones y cuando los hechos publicados afecten perjudicialmente a los intereses del demandante aludido por la información".

Como apunta M. CARRILlo, "Libertad de expresión...", op.cit.pág. 59, el periodista sabe que no podrá ser compelido judicialmente a rectificar opiniones o juicios, vertidos por él en ejercicio de su profesión, salvo que haya incurrido en responsabilidades civiles o penales, sin embargo, "deducir de ello el triunfo de los periodistas sobre los políticos (...) es, cuanto menos distorsionador del auténtico sentido de este derechon.

Por otro lado, el dictamen de la Comisión de Justicia e Interior del Congreso aceptó una enmienda del Grupo Popular cuyo objeto era incluir en la rectificación no sólo los hechos, sino también los juicios de valor. El Pleno del Congreso aprobó el dictamen. Sin embargo, en el Senado se cambió el criterio, curiosamente también a instancia del Grupo Popular, considerando que son los hechos los que han de ser rectificados. Este último sería aprobado definitivamente por el Congreso.

25 P. LAX, I/ diritto..op. cit. pág. 21, sostiene que: "se permite al sujeto afectado por la noticia enriquecer, mediante nuevas informaciones o con la realización de una interpretación diversa de las circunstancias de hecho de la información (...) para completar el conocimiento de los hechos de parte de la colectividad". 
Finalmente, se contempla en la Directiva de la Comunidad Europea de 3 de octubre de $1989^{30}$, y en Convenio Europeo sobre Televisión transfronteriza, de 5 de mayo de $1989^{31}$.

\subsection{El derecho de rectificación y el Convenio Europeo}

Por último, debemos tener en cuenta que este derecho debe ser interpretado a la luz del art. 10 del Convenio Europeo para la Protección de los Derechos Humanos y de las Libertades Fundamentales que reconoce:

«1. Toda persona tiene derecho a la libertad de expresión. Este derecho comprende la libertad de opinión y la libertad de recibir o de comunicar informaciones o ideas que sin que pueda haber injerencia de autoridades públicas y sin consideración de fronteras (...).

2. El ejercicio de estas libertades que entrañan deberes y responsabilidades, podrá ser sometido a ciertas formalidades, condiciones, restricciones o sanciones previstas por la ley, que constituyan medidas necesarias, en una sociedad democrática, para la seguridad nacional, la integridad territorial o la seguridad pública, la defensa del orden y la prevención del delito, la protección de la salud o de la moral, la protección de la reputación o de los derechos ajenos, para impedir la divulgación de informaciones confidenciales o para garantizar la autoridad y la imparcialidad del poder judicial».

30 Ver al respecto $M$. Desantes Guanter, «El llamado derecho de réplica en la Directiva de la CE de 3 de octubre de 1989», en Noticias CEE, junio 1991, núm. 77, págs. 73-79.

31 En este Convenio se regula el "derecho de réplica", cuyo contenido coincide con nuestro derecho de rectificación.

Al respecto el art. 8 del mismo prevé: «1. Cada Parte transmisora se asegurará de que toda persona física o jurídica, cualquiera que fuere su nacionalidad o su lugar de residencia, pueda ejercer un derecho de réplica o tener acceso a otro recurso juridico administrativo equiparable con respecto a las emisiones transmitidas o retransmitidas por organismos o con ayuda de medios técnicos que dependan de su jurisdicción (..). Cuidará en particular de que el plazo y las modalidades previstas para ejercer el derecho de réplica sean suficientes para permitir el ejercicio efectivo del derecho de réplica. El ejercicio efectivo de este derecho o de otros recursos jurídicos o administrativos equiparables deberá estar asegurado tanto desde el punto de vista de los plazos como por lo que se refiere a las modalidades de aplicación.

2. A tal efecto, el nombre del radio difusor responsable será identificado a intervalos regulares por medio de todas las indicaciones adecuadas.” 
El derecho de rectificación, superando su original función de defensa de los derechos o intereses del rectificante, en cuanto que el Tribunal Constitucional lo ha considerado como «el mecanismo más idóneo para reparar (...) lo que pudiera constituir intromisión en el derecho al honor ${ }^{32}$, supone asi, un medio de restablecer la verdad de los hechos, una garantía más de la existencia de la opinión pública libre, que establece el art. 20.1.d) CE, cumpliendo una función reequilibratoria. Con él se satisface bien la esfera personal -honor, reputación...- del sujeto agente, bien el interés del público en una información completa e imparcial. Este segundo papel está íntimamente ligado al papel fundamental de la información en el funcionamiento y en el desarrollo del orden democrático al ser el instrumento de la formación de la opinión pública ${ }^{33}$.

\section{EL DERECHO DE RECTIFICACIÓN Y EL PROCESO ELECTORAL}

Cuando la difusión de ciertas informaciones, por cualquier medio de comunicación social ${ }^{34}$, tenga lugar durante el desarrollo del proceso electoral ${ }^{35}$, y aluda, de manera concreta o abstracta a hechos que afec-

\section{SSTC $35 / 1983$ y 40/1992.}

33 P. LAX, II diritto...op.cit.pág. 22.

34 La exigencia de que se haya difundido la información supone la existencia de una noticia escrita o gráfica de un hecho o un dicho siendo indiferente que se divulgue en un suelto específico, o en un programa de radio o televisión especial, que se contenga en un artículo, trabajo o editorial más amplio,que vaya o no firmado, que se haya distribuido por Agencia, se haya incluido en espacios pagados o gratuitos.

No se consideran incluidas en el ámbito de la LO 2/1984 la informaciones inexactas difundidas en impresos o folletos no periódicos, libros, videos, cintas grabadas, emisoras piratas, por telex, telégrafo, ni, lo que es más importante a los efectos que nos interesan, en una conferencia o mitin público. Puede verse una relación del tipo de informaciones afectadas por la LO 2/1984 en J. TOMÉ PAULE, "La rectificación...",op.cit.pág. 72.

Las informaciones cuya vía de difusión haya sido "La red» no pueden considerarse incluidas en el ámbito de la LO 2/1984 por tanto, ni estamos ante un "medio de comunicación social», ni la inclusión de la versión disidente depende del "Director" del medio.

35 En el art. 68 LOREG no se especifica si se refiere a todo el "periodo electoral's, esto es, los 54 dias que median desde la Convocatoria hasta la votación, o a parte de este. Pero, si tenemos en cuenta que se dice que los sujetos activos del derecho de rectificación serán "candidatos o dirigentes (...) que concurran a la elección", se referirá exclusivamente a quienes pertenezcan a las candidaturas proclamadas, que son las que, efectivamente, concurren. La proclamación tiene lugar el 
ten a sus actores, (si estos los consideran inexactos y estiman que pueden causarles perjuicio) ${ }^{36}$ en el caso de que decidan ejercer el derecho de rectificación previsto en la LO 2/1984, deberá tenerse en cuenta la regulación específica del derecho, establecida en el art. 68, situado en la Sección VII del Capítulo VI de la LOREG dedicado al "Derecho de rectificación».

En este precepto se hace alusión, exclusivamente, a los candidatos y/o dirigentes de los partidos, federaciones, coaliciones o agrupaciones concurrentes y actúa como garantía de la veracidad de la información que recibe el Cuerpo Electoral, información que le ayudará decidir a quién, de entre todos los candidatos que integran las fuerzas concurrentes, va a otorgarle su voto.

El referido art. 68 LOREG, que recoge en su totalidad el Texto del Proyecto de Ley, además, no ha sido modificado desde la entrada en vigor de la Ley electoral, por lo que podríamos pensar que o bien no ha debido plantear problemas de aplicación que hayan hecho aconsejable alguna alteración de su contenido, o bien no existen problemas relativos a la veracidad informativa en este ámbito ${ }^{37}$.

\subsection{Especialidades}

Cuando se den las circunstancias previamente expuestas, el derecho de rectificación será ejercitable de conformidad con la regulación contenida en la citada LO 2/1984, aunque, con ciertas particularidades. En primer lugar, entendemos que estas especialidades se refieren solo

vigésimo séptimo día posterior a la Convocatoria, ex art. 47.3 LOREG. Consideramos, por tanto, que será a partir de ese momento cuando los sujetos a los que se refiere el art. 68 LOREG se benefician de las previsiones contenidas en la Ley electoral.

36 Deberán cumplirse ambos presupuestos: considerarse los hechos inexactos y que estos sean susceptibles de causar perjuicio al sujeto aludido. Sin embargo, como la apreciación de la inexactitud es totalmente subjetiva, también es posible que, en el caso de que puedan irrogar algún perjuicio, el afectado intente dar una versión que le favorezca más que la que ha sido difundida aunque sea, esencialmente cierta, porque, como hemos dicho, no se le exige una demostración de la certeza de los hechos que comunica, o más bien, de su interpretación de los mismos. En todo caso si el Director del medio considera que la explicación del rectificante no es sino una apreciación subjetiva, deberá aportar los elementos probatorios ante el correspondiente órgano judicial que deberá realizar la valoración de los hechos y la calificación de las valoraciones. Ver ATC 204/1991.

37 En el Texto del Proyecto de Ley Orgánica de Régimen Electoral General, se recogía en el art. 67. 
a personas naturales, pues el tenor literal del art. 68.1 LOREG refiriéndose a "candidatos o "dirigentes", no puede hacerse extensiva a las personas jurídicas, que sí que están incluidas en el art. 1 de la LO $2 / 1984$. Tampoco parece viable la la posibilidad de que ejerciten el derecho los herederos o los representantes ${ }^{38}$.

El resto de singularidades a las que vamos a referirnos encuentran su fundamento en las exigencias temporales que impone la determinación de los plazos del proceso electoral. En la propia Ley electoral establece:

"a) Si la información que se pretende rectificar se hubiera difundido en una publicación cuya periodicidad no permita divulgar la rectificación en los tres días siguientes a su recepción, el Director del medio de comunicación deberá hacerla publicar dentro del plazo indicado en otro medio de la misma zona y de similar difusión.

b) El juicio verbal regulado en el párrafo segundo del art. 5 de la mencionada LO 2/1984 se celebrará dentro de los cuatro días siguientes al de la petición.»

Otra particularidad del ejercicio del derecho de rectificación en periodo electoral consiste en el plazo previsto para la difusión de la aclaración del rectificante. En primer lugar, con carácter general, la LO 2/1984 prevé que se llevará a cabo la remisión del escrito de rectificación al Director del medio de comunicación, envío que tendrá lugar dentro de los siete días naturales siguientes al de la publicación, o emisión, de la información que se desea rectificar ${ }^{39}$. El Director deberá or-

38 De este modo parece que los partidos, federaciones, coaliciones o agrupaciones de electores no estarían legitimados. Aunque la información afectase a estos en general sin concretar a las personas físicas que los integran o dirigen. En estos casos, pensamos que se acudiría a la regulación general contenida en la LO 2/1984, que si los legitima activamente.

${ }_{39}$ Sólo se exige que este derecho se ejercite por escrito, sin someterse a requisitos formales de ningún tipo, siempre que se tenga constancia de su fecha $y$ de su recepción. De este modo está claro que se admitiria el telégrafo y el fax. Creemos que también el cada vez más utilizado e-mail, sería un medio apropiado porque queda constancia de la fecha de emisión, aunque es más difícil que quede constancia de la recepción y del contenido del mismo.

De otro lado, puede plantear algunos problemas el hecho de que el aludido esté en el extranjero o si la noticia se ha dado en un programa radiofónico que, o bien han escuchado terceras personas que le ponen sobre aviso, pero no tienen la información exacta. Más difícil que ocurra, pero no imposible, que es que en la emisora no localicen la grabación del mismo con lo que se dificultaria el cumplimiento del plazo. 
denar la publicación, o difusión, íntegra de la rectificación en los tres días siguientes que se llevará a cabo con una relevancia semejante a la que tuvo aquélla en que se publicó o difundió la información que se rectifica ${ }^{40}$. Está completamente prohibido interpolar comentarios o apostillas ${ }^{41}$.

Según la previsiones contenidas en la LO 2/1984, si la información que se rectifica se difundió en publicación cuya periodicidad no permita la divulgación de la rectificación en el plazo expresado, el escrito remitido por el rectificante se publicará en el número siguiente. Sin embargo, en el caso de que la noticia o información que se pretenda rectificar se hubiese difundido en un espacio radiofónico o de televisión que no permitiese, por la periodicidad de su emisión, divulgar la rectificación en el plazo de tres días, podrá exigir el rectificante que se emita, en espacio de audiencia y relevancia semejantes, dentro de dicho plazo. Y ello en virtud de la extendida consideración de que las características de dichos medios de comunicación permiten que la difusión de la rectificación, aunque no se haga en el mismo espacio que emitió la noticia, tenga unas repercusiones similares.

El legislador electoral introdujo esta especialidad en virtud de la perentoriedad de las fases del itinerario electoral, que no puede esperar a la aparición del número siguiente de una publicación mensual, trimestral, y muchas veces ni siquiera si la misma es de aparición semanal, pues el acto fundamental al que pudiera afectar la información - decisión del elector y el consiguiente apoyo a un determinado candidato- ya se habría realizado. Así, en el supuesto de que la noticia hubiese sido publicada, y el escrito de rectificación no pudiese divulgarse en los tres días siguientes a su recepción el Director deberá hacerla publicar, a su costa, dentro del plazo indicado en otro medio de la misma

40 El escrito de rectificación no deberá exceder sustancialmente el de la información, salvo que sea absolutamente necesario, según dispone el art. 2.2 LO $2 / 1984$. Esta flexibilidad proporciona más problemas que otra cosa puesto que no se determina quien deberá determinar la idoneidad de la extensión. En el caso de que la rectificación no se hubiese difundido «íntegramente", podrá ejercerse la acción de rectificación. Entonces, ¿Qué ocurre si excede notablemente la extensión de la noticia rectificada? ¿Deberá instarse al rectificante a que la reduzca? ¿Reducirá el Director su extensión?, ¿Dejará de publicarse?.

41 Art. 3 LO 2/1984.

Como indica J. Tomé PAULE, "La rectificación...", op. cit. pág. 75, por comentario debe entenderse las palabras que sirvan de explicación a la rectificación y por apostilla la acotación que interpreta, aclara o completa un texto publicado o emitido y suele ponerse al margen o a continuación. Considera que no existe una prohibición absoluta, pues sólo se refiere al momento de la inserción o difusión. 
zona y de similar difusión pues el único medio de que su efectividad no sea nula. Al menos con ello se salvaría una de las finalidades del derecho, la contribución a la formación de la opinión pública, porque la reparación de los derechos del sujeto afectado puede conseguirse, como veremos, por otros medios.

No obstante, no se nos escapa que los lectores de una determinada publicación, y también los oyentes de un programa o televidentes, suelen mantenerse fieles a los mismos, y no es probable que se interesen por el contenido de otra publicación o emisión similar. Consecuentemente, la eficacia de la previsión contenida en la Ley electoral sería cuestionable desde esta perspectiva: no habría demasiadas posibilidades de que los lectores o espectadores que hubieran recibido la primera información pudiesen comparar ambas versiones sobre un mismo hecho sino que habria dos versiones y cada una de ellas llegaría a una parte del Cuerpo Electoral. Con todo, es cierto que no cabe otra solución si la rectificación ha de hacerse de nuevo en una publicación, y no existe la posibilidad de hacerlo en un espacio radiofónico o de televisión y no aparece un nuevo número hasta pasados los tres días desde que se publicó la información controvertida.

Otro problema relativo a la eficacia práctica actual del derecho de rectificación, deriva del peligro de que, en caso de que no se cumpla la obligación impuesta al Director del medio, o se cumpla defectuosamente, y dado que deberá ejercitarse la acción de rectificación, con el consiguiente transcurso de tiempo, vital en el caso del proceso electoral, incluso una sentencia favorable puede resultar ineficaz ${ }^{42}$. Eso lo veremos en el apartado siguiente.

\section{LA ACCIÓN JUDICIAL DE RECTIFICACIÓN}

Como hemos indicado, si dentro de los plazos previamente señalados no se hubiese publicado o divulgado el escrito de rectificación, o bien se hubiese notificado expresamente por el Director o responsa-

42 Si contabilizamos siete días para interponer la demanda y cuatro celebrar el juicio, a lo que se añaden los aproximadamente diez que ya han transcurrido, suponemos que toda información que aparezca una vez iniciada la campaña electoral, que sabemos dura quince dias y termina veinticuatro horas antes de la votación,ex art. 50 LOREG, apenas tendrá posibilidad de ser rectificada si no se cuenta con la buena voluntad del Director del medio. Situación que se agrava cuando éste mantiene una tendencia ideológica determinada en la publicación. 
ble del medio de comunicación social que aquél no sería difundido; 0 , en el caso de que se hubiese publicado o divulgado, pero se hubiere hecho sin respetar las condiciones señaladas -la rectificación no se publica íntegramente, no se le da la relevancia requerida, cuando se publica con comentarios o apostillas, o se hace fuera de plazo- el perjudicado podrá ejercer la acción de rectificación, según lo dispuesto en la LO $2 / 1984$, excepto en lo que respecta a la duración del juicio verbal ${ }^{43}$.

La Ley prevé una tutela jurisdiccional en caso de conflicto, y una vez agotada la vía jurisdiccional ordinaria, podrá interponerse recurso de amparo constitucional ${ }^{44}$. La acción de rectificación se convierte en un derecho de carácter eminentemente público y procesal para garantizar el derecho de rectificación. Es asimismo, un derecho fundamental por cuanto el art. $24 \mathrm{CE}$ concede a todos el derecho de obtener la tutela judicial efectiva de los jueces y tribunales en el ejercicio de sus derechos ${ }^{45}$.

\subsection{Competencia}

La competencia objetiva la ostenta en todo caso el Juez de Primera Instancia y la territorial se determina a través de un doble criterio del lugar del domicilio del demandante o del lugar donde radique la dirección del medio de comunicación, a elección del demandante ${ }^{46}$.

\subsection{Procedimiento}

Presentada la demanda, $y$ sin haber dado traslado de la misma al demandado, el Juez examinará su propia competencia objetiva o territorial, estando facultado para inadmitirla cuando se incumpla este pre-

43 Consideramos más adecuado que, una vez el Director no cumple con su obligación de insertar la rectificación, se pase directamente a la vía jurisdiccional y no se articule una vía administrativa previa, que lo único que haria sería, en su caso, demorar la aparición de la otra versión. Así ocurria en el E.R.T.V. art. 32, en que la denegación podía ser recurrida ante el Consejo de Administración que, cuya resolución pondrá fin a la vía administrativa

${ }_{44}$ En este sentido M. CARRILLO, "Libertad de expresión....", op. cit. pág. 63. No obstante, considera que lo que se reivindica es el derecho a la libertad de expresión reconocido en el art. $20 \mathrm{CE}$, al calificar el derecho de rectificación "derecho integrante de la libertad de expresión".

45 J. Tomé Paule, "La rectificación...", op. cit. pág. 78.

46 Art. 4 LO 2/1984. 
supuesto procesal ${ }^{47}$. El Juez, de oficio y sin audiencia del demandado, dictará auto no admitiendo a trámite la demanda en el caso de que se considere incompetente o estime que la la rectificación resulta manifiestamente improcedente ${ }^{48}$. En el primer supuesto, el perjudicado podrá acudir al órgano competente dentro de los siete días hábiles siguientes al de la fecha de notificación de la correspondiente resolución. En ésta se deberá indicar el órgano al que corresponda el conocimiento del asunto ${ }^{49}$.

\subsection{Juicio verbal}

En caso de admitir la demanda, el Juez convocará al rectificante y al Director del medio de comunicación, o a sus representantes, al juicio verbal que se celebrará dentro de los cuatro días siguientes al de la petición ${ }^{50}$. Para ganar tiempo, la convocatoria se realizará telegráficamente, sin perjuicio de la remisión por cualquier otro medio de la copia de la demanda a la parte demandada.

El juicio se tramitará de conformidad con lo establecido en el Libro Segundo, rotulado "De la jurisdicción contenciosa», Título II, Capítulo IV, "Del juicio de menor cuantía", de la Ley de Enjuiciamiento Civil para los juicios verbales, aunque con algunas modificaciones ${ }^{51}$. La sumariedad del proceso verbal exime al Juzgador de una completa indagación de la veracidad tanto de los hechos difundidos o publicados, como del contenido del escrito de rectificación ${ }^{52}$.

\section{Art. 5 LO 2/1984.}

48 El auto que el mismo puede dictar no admitiendo a trámite la demanda en caso de que se considere incompetente o por estimar la rectificación manifiestamente improcedente.

De este modo, "la Ley asegura una celeridad en el procedimiento evitando que se inicie de forma gratuita y con finalidades extrañas a la propia rectificación", según M. CARRILLo, "Libertad de expresión...", op. cit. pág. 64. No obstante, para evitar la indefensión, la resolución es apelable en ambos efectos.

49 Ver STC 168/1986: "El derecho de rectificación además de su primordial virtualidad de defensa de los derechos o intereses del rectificante, supone un complemento a la garantía de la opinión pública libre».

50 En el art. 5.2 de la LO 2/1984 el plazo para celebrar el juicio es de siete días, pero, por los motivos tantas veces aludidos, en el caso de materia electoral este plazo se reduce en tres días.

51 Arts 715 a 740 LEC.

52 Ver STC 168/1986.

Si se plantea el problema del grado de verificación de la veracidad de la notícia $y / o$ rectificación pretendida exigible a los órganos judiciales en este especial 
La acción se ejercitará mediante escrito sin necesidad de Abogado ni Procurador debido a que el procedimiento adecuado es el juicio verbal $^{53}$. La sustanciación de este juicio verbal se llevará a cabo de una forma especialmente rápida. Esta celeridad procedimental se justifica en la finalidad preventiva que cumple el procedimiento tendente a evitar el perjuicio que una determinada información pueda irrogar. La legítima finalidad preventiva -independiente de la reparación del daño causado por la difusión de una información que se revele objetivamente inexacta- podría quedar frustrada en el caso en que se demorara la rectificación pretendida, pero también podria frustrarse la contribución de la información a la formación de la opinión pública. De ahí, que el trámite deba ser sumario ${ }^{54}$.

Si estas conclusiones resultan aplicables a la generalidad de los casos, con más razón, cuando la presunta lesión se produzca en relación a uno de los actores del proceso electoral, cuyas fases van discurriendo inexorablemente hasta el momento fundamental de la emisión del voto, de suerte que deviene imprescindible que la reparación se produzca de inmediato.

\subsection{Demanda}

La demanda ${ }^{55}$, se interpondrá mediante un escrito en papel común y contendrá los nombres, domicilio, profesión u oficio del demandante ${ }^{56} y$ demandado o demandados, la pretensión que se deduce, la fecha en que se presenta al Juzgado y la firma del quien la presente.

procedimiento, "cuando la veracidad de la versión publicada sea patente, por haber sido contrastada judicialmente, por ser de dominio público u otras circunstancias similares 0 , en sentido inverso, cuando la versión del rectificante carezca por completo de verosimilitud, por ser absurda arbitraria o caprichosa, es claro que el Juez puede rechazar la demanda, pues el método de verificación de la verdad no conlleva siempre el procedimiento dialéctico, sino sólo cuando no son de aplicación los presupuestos de verificación que exigen un mínimo de probabilidad a una pretensión de verdad». Sentencia de 22 de septiembre de 1992 de la Audiencia Prov. de Madrid.

53 Art. 5 LO 2/1984.

54 STC $168 / 1986$

55 En la LO 2/1984 se le denomina escrito por cuanto se trata de una demanda informal que deberá extenderse en papel común y contener los datos de identificación de las partes.

56 Recordamos que sólo los demandantes que se detallan en el art. 68 LOREG se beneficiarán de la extrema brevedad de los plazos previstos en el mismo precepto. 
El demandante acompañará tantas copias de la demanda cuantos sean los demandados. Presentado el escrito que deberá acompañarse de la información rectificada si se difundió por escrito y en otro caso la reproducción o una descripción lo más fiel que sea posible ${ }^{57}$.

Dentro del segundo día el Juez dictará providencia convocando a las partes a una comparecencia y señalará día y hora al efecto. Entre la citación y la celebración de la comparecencia deberá transcurrir un periodo de tiempo que no sea inferior a veinticuatro horas pero que no exceda de seis días.

La comparecencia se celebrará ante el Juez y el Secretario el día señalado. En ella expondrán las partes, por su orden, lo que pretendan con la especialidad de que sólo se admitirán las pruebas que, siendo pertinentes, puedan practicarse en el acto ${ }^{58}$. El Juez podrá reclamar, de oficio, que el demandado remita o presente la información enjuiciada, su grabación, o reproducción escrita ${ }^{59}$.

\subsection{Sentencia}

Celebrada la comparecencia, el Juez dictará sentencia definitiva en el mismo día o al siguiente del juicio ${ }^{60}$. El fallo se limitará a denegar la rectificación o a ordenar su publicación, o difusión, en la forma y plazos anteriormente expuestos, los cuales empiezan a contar desde la notificación de la sentencia.

La Ley dispone que se impondrá el pago de las costas a la parte cuyos pedimentos hubiesen sido totalmente rechazados. Lo que no deja de presentar problemas por cuanto, cabe la posibilidad de estimar parcialmente la demanda ${ }^{61}$. La sentencia estimatoria de la petición de rectificación deberá cumplirse en sus propios términos.

57 Con esta previsión se salvan, en principio, los problemas que pueden surgir de la imposibilidad de obtener copia de la información polémica.

58 Art. 6.a) LO 2/1984.

59 El Juez da al Director un plazo para que cumpla el requerimiento, plazo que necesariamente habrá de ser breve. Si el Director no cumple se dictará sentencia sin que tal actitud pueda originar menoscabo del derecho del actor.Ver J. TOMÉ PAULE, "La rectificación...", op. cit. pág. 83.

60 Art. 6.c) LO 2/1984 que presenta una modificación respecto a lo dispuesto en el art. 731 LEC que posibilita al Juez para dictar sentencia hasta en los tres días siguientes.

61 Como indica J. TOMÉ PAULE, "La rectificación...", op. cit. pág. 83, "esta facultad no viene prevista en la $L O$ pero es norma general del principio de congruencia limitador de la actividad del juez». 
Esta sentencia, que obliga a la inserción de la rectificación no puede considerarse como una sanción jurídica derivada de la inexactitud de lo publicado, «Por el contrario, la simple inserción de una versión de los hechos distinta y contradictoria ni siquiera limita la facultad del medio a ratificarse en la información inicialmente suministrada o, en su caso, aportar y divulgar todos aquellos datos que la confirmen o avalen ${ }^{62}$.

Con todo, la rectificación judicialmente impuesta de una información que el rectificante considera inexacta y lesiva a sus intereses no menoscaba el derecho fundamental proclamado en el art. 20.1.d) $C E$, ni siquiera en el caso de que la información que haya sido objeto de rectificación pudiera, a posteriori, revelarse como cierta ${ }^{63}$.

Según el Tribunal Constitucional, la sumariedad del proceso verbal exime al juzgador de una indagación completa tanto de la veracidad de los hechos difundidos o publicados, como de la que concierne a los contenidos en la rectificación, de lo que se deduce que, en aplicación de dicha Ley, puede imponerse la difusión de un escrito de réplica o rectificación que posteriormente pudiera revelarse no ajustado a la verdad. De ahí que, la resolución judicial que estima una demanda de rectificación, no garantiza en absoluto la autenticidad de la información presentada por el demandante ni puede tampoco producir, como es obvio, efectos de cosa juzgada respecto de una ulterior investigación procesal de los hechos efectivamente ciertos ${ }^{64}$. La investigación de la verdad y la declaración de las informaciones como ciertas siempre podrá instarse y determinarse a posteriori a través de los procedimientos que el ordenamiento jurídico arbitra al respecto.

Contra la sentencia cabe recurso de apelación en la forma establecida por la Sección tercera del Título VI del Libro II de la Ley de Enjuiciamiento Civil65. Finalmente, no podemos olvidar que en caso que

62 ATC 70/1992.

63 STC $168 / 1986$.

64 STC 168/1986. En este mismo sentido la STS de 27 de enero de 1992.

65 La apelación de la sentencia de admite en un solo efecto, lo que, en el caso de que tras el recurso de apelación se revoque la sentencia la revocación no podrá tener eficacia. J. ToMé PAULE, «La rectificación....", op. cit. pág. 83.

Al respecto, resulta interesante la observación de F. Igartua Arregu, "Comentario a la Sentencia de la Audiencia de Barcelona de 17 de mayo de 1986: lagunas en la normativa del derecho de rectificación" en Poder Judicial , núm. 4, pág. 118. Hace notar como en algunas sentencias se parte de la aceptación del recurso de apelación en ambos efectos, esto es, se puede suspender la ejecución de la sentencia de instancia y, por tanto, la publicación de la rectificación por un largo periodo, lo que puede destruir la finalidad del derecho a la rectificación. 
ésta sea estimatoria, pero en el caso de que el Director del medio decida no cumplirla cabría una sanción penal66.

\section{LA ACCIÓN DE RECTIFICACIÓN Y EL DERECHO AL HONOR}

El derecho de rectificación se satisface con la publicación íntegra de y gratuita de la rectificación de los hechos contenidos en la información difundida. Este es, además de una garantía de la veracidad de la información, y a los efectos que ahora nos interesan, sólo un medio para prevenir o evitar un posible perjuicio que aquélla puede causar en el honor de una persona ${ }^{67}$, daño que será reparable por otras vías ${ }^{68}$.

Así, la acción de rectificación resulta compatible con el ejercicio de acciones civiles o penales que pudieran asistir al perjudicado por los hechos difundidos ${ }^{69}$. En cuanto a las primeras, están previstas en la LO 1/1982 de Protección Civil del Derecho al Honor, a la Intimidad Personal

66 Asi se pronuncia J. TOMÉ PAULE, "La rectificación...", op. cit. pág. 84.

No es extraño este supuesto, y sirva a título de ejemplo lo que aconteció cuando el Juzgado de Primera Instancia núm.21 de Madrid que, en su sentencia de 15 de diciembre de 1984, al estimar el recurrente, en este caso el PSOE, que no había sido cumplida por la parte demandada sino muy deficientemente solicitó su cumplimiento. Tras diversos recursos, el Auto de la Sala Primera de lo Civil de la Audiencia territorial de Madrid de 14 de mayo de 1987,considerando que la Sentencia no había sido cumplida sino muy deficientemente $y$ ante la imposibilidad de repetir la rectificación integra dado el tiempo transcurrido, por haber perdido ya su valor, concedió al PSOE una indemnización de daños y perjuicios derivado del incorrecto cumplimiento de la Sentencia que imponía la rectificación. Ver ATC $578 / 1988$.

Ello no impide, por otro lado que al ejercer la acción civil prevista en la LO $1 / 1982$, se pueda volver a condenar al medio a pagar una indemnización al afectado, en este caso por lesiones infligidas en su derecho al honor.

67 Cuando el informador no contrasta las fuentes de la noticia, y de la publicación de la misma se derivan perjuicios para el honor o fama de un tercero, independientemente de que se haya ejercido o no el derecho de rectificación, podrán ejercerse las acciones que pudieran asistir al perjudicado. STC 52/1996.

68 Cabría preguntarse si el ejercicio de la acción encaminada a proteger el derecho al honor exige como requisito previo el que el interesado procure la rectificación de la información errónea. La respuesta es clara: de ningún modo se impone tal deber, únicamente, en la STC 35/1983 (es interesante la aclaración contenida en el ATC 94/1989) se indica que, de intentarse la vía de rectificación la vulneración del derecho al honor sólo se originaría a partir del momento en que el derecho de rectificación quedara frustrado, pues a través de la rectificación hubiese podido ser sanado y la negativa del medio consolida el daño.

69 Art. 6 LO 2/1984. 
y Familiar y a la Propia Imagen. El art. 9.2 de la misma preceptúa que la tutela judicial comprenderá la adopción de todas las medidas necesarias para poner fin a la intromisión ilegítima de que se trate e indispensables para restablecer al perjudicado en la plena posesión de sus derechos, así como prevenir o impedir intromisiones ulteriores.

Entre estas medidas se pueden incluir las cautelares, encaminadas al cese inmediato de la intromisión ilegítima, el reconocimiento del derecho de rectificación, la difusión de la sentencia en el medio de comunicación en que se haya cometido la intromisión y la condena a indemnizar los perjuicios causados. En este precepto, la Ley hace una mezcla de las medidas cautelares y de las que puede interponer definitivamente la sentencia, como la rectificación, la publicación de la sentencia condenatoria y la indemnización. De otro lado, cuando se refiere al cese inmediato de la intromisión ilegítima no detalla cómo se debe hacer, pero tampoco lo hace cuando se trata de prevenir o impedir intromisiones ulteriores.

Una de las posibilidades del Juez es suspender hasta que se dicte la sentencia, y por decisión propia, la publicación de la información o la difusión audiovisual cuando la demanda se ha interpuesto antes de que se publique o difunda. Una decisión en este sentido no es frecuente pues las intromisiones suelen ser conocidas por los agraviados después de cometidas. Una excepción pueden ser los programas de radio o televisión que ya están grabados y todavía no se han emitido ${ }^{70}$.

La suspensión judicial podría ser acordada también a solicitud del demandante, siguiendo el procedimiento del art. 1428 de la LECrim. En este supuesto, el demandante habría de prestar fianza suficiente para responder de la indemnización de daños y perjuicios que la suspensión pudiera causar al demandado en el caso de una sentencia favorable a éste ${ }^{71}$. En su Disposición Transitoria Segunda se prevé que en tanto no sean desarrolladas las previsiones del art. 53.2 CE sobre establecimiento de un procedimiento basado en los principios de preferen-

70 En la STS de 13 de julio de 1992 se plantea el problema, de modo que I Tribunal estima que si antes de que se emita el programa grabado se sabe o se comprueba, comprobación de otro lado ineludible, que las informaciones que se proporcionan no son ciertas y /o el entrevistado se ha retractado no deben emitirse.

71 Ll. de Carreras Sierra, Régimen...,op. cit. pág. 150. Opina que que la fianza que se fijaría sería tan elevada que no es probable que esto suceda. Habría que pensar en el perjuicio que sufriría el el editor de un periódico no sólo representaría dejar de percibir el precio de los ejemplares sino también el de publicidad... etc. En el caso de radio televisión se añadirían las tarifas publicitarias dejadas de percibir, el coste de programa suspendido y el coste del programa que lo sustituya. 
cia y sumariedad, la tutela judicial de los derechos al honor, intimidad personal y propia imagen se podrá recabar -con las peculiaridades pertinentes- por cualquiera de los procedimientos establecidos en las Secciones II y III de la Ley 62/1978, de 26 de diciembre, de Protección Jurisdiccional de los Derechos Fundamentales de la Persona. Agotado el procedimiento seguido, quedará expedito el recurso de amparo constitucional en los supuestos a que se refiere el Capítulo I del Título III de la Ley Orgánica 2/1979 de 3 de octubre, del Tribunal Constitucional.

\section{LA ACCIÓN DE RECTIFICACIÓN Y LOS DELITOS DE CALUMNIAS E INJURIAS}

Como hemos señalado, la LO 2/1984 advierte que este proceso es compatible con el ejercicio de las acciones penales pertinentes por los delitos de calumnia e injurias ${ }^{72}$. Así, la admisión de una demanda de rectificación no impide que el afectado ejercite las acciones civiles (vistas en el apartado anterior) ni penales. A este respecto, queremos subrayar que la Ley electoral introduce una modificación en relación a los delitos de calumnias o injurias que se cometan en periodo de campaña electoral y con motivo $u$ ocasión de ella, en relación a las penas privativas de libertad previstas en el Código Penal, las cuales se impondrán en su grado máximo ${ }^{73}$.

Según la Ley electoral, la campaña comienza el trigésimo octavo día posterior a la convocatoria y dura quince días, terminando, en todo caso, a las cero horas del día inmediatamente anterior a la votación $^{74}$. Por otro lado, aunque no cabe realizar actos de campaña electoral una vez concluida ésta, si cabe la publicación o difusión de referencias a los actos de campaña electoral realizados el día de cierre de la misma, por estar dicha información el día de reflexión amparada

72 Art. 216 CP.: "En los delitos de calumnia o injuria se considera que la reparación del daño comprende también la publicación o divulgación de la sentencia condenatoria, a costa del condenado por tales delitos, en tiempo y forma que el Juez o Tribunal consideren más adecuado a tal fin".

La calumnia es un tipo penal en que la falsedad de una determinada imputación constituye un elemento esencial de la integración del injusto. En la injuria sólo se admite la prueba de la verdad en aquéllas consistentes en la imputación falsa de un delito de los que dan lugar a procedimiento de oficio y en las dirigidas contra funcionarios públicos sobre hechos concernientes al ejercicio de su cargo.

73 Art. 148 LOREG.

74 Art. 51 LOREG. según redacción dada por la LO 13/1994 de 30 de marzo. Con anterioridad, podía durar un minimo de quince dias y un máximo de veintiuno. 
por la libertad de expresión y el derecho a la información reconocidos en el art. $20 \mathrm{CE}$, siempre que aquellas referencias no constituyan propaganda electora $\mathrm{P}^{75}$.

Esta agravación de los delitos de calumnia e injuria en el marco de la campaña electoral fue recogida, no en el RDL 20/77, como cabría esperar, sino en el RDL 24/77 de 1 de abril, sobre libertad de expresión, en su artículo 5 cuyo tenor literal era el siguiente:

"Cuando los delitos de calumnia (...) se cometan en periodo de campaña electoral y con motivo u ocasión de aquella, las penas privativas de libertad previstas al efecto en el Código Penal se impondrán en su grado máximo.

En los supuestos de injurias graves cometidas por escrito y con publicidad, el Tribunal, teniendo en cuenta las circunstancias concurrentes podrá imponer la pena privativa de libertad inmediatamente superior a la prevista en el Código Penal, en su grado mínimo. Esta agravación se producirá en todo caso, cuando el delito se realice durante el periodo de campaña electoral y con motivo u ocasión de ella.»

La duración de este RDL fue realmente corta al ser derogado por la Ley 62/1978 de 26 de diciembre que no recogía agravación en el caso de que dichos delitos se perpretaran con motivo u ocasión de la campaña electoral. No obstante, el texto se recogió en el citado artículo de la LOREG.

En nuestra opinión, si bien por una parte deberá garantizarse la limpieza del proceso electoral evitando que algunos candidatos puedan proporcionar informaciones que, a la vez que dañan el honor de sus contrincantes, impiden que impere el principio de igualdad a la hora de acceder a los cargos públicos pues perturban la libre formación de la voluntad del Cuerpo Electoral ${ }^{76}$. por otra, no podemos obviar que con la actual regulación se favorece una mayor limitación del derecho a la información y de la libertad de expresión de dichos candidatos ${ }^{77}$.

75 AAJEC de 10 de marzo y 2 de junio de 1986, de 5 de junio y 26 de octubre de 1989, de 2 y 17 de junio de 1993.

En relación a la publicidad electoral es un ámbito muy especifico, las elecciones municipales, ver L. JIMENA QUESADA, "La campaña electoral y el derecho de antena en las radios municipales", en Cuadernos de la Cátedra Fadrique Furió Ceriol, núm.4, 1993, págs. 87-109.

76 Ver art. 23.2 CE y art. 8 LOREG.

77 En contra de la aplicación de sanciones penales a las extralimitaciones del ejercicio de la libertad de expresión el Magistrado VIVES ANTÓN se ha pronunciado en diversos votos particulares. Así, SSTC 76/1995, 78/995 o 46/1998. 
Estamos, pues, ante la disyuntiva de primar la protección del derecho a la libertad de expresión o de la limpieza del proceso electoral. Si nos decantamos por esta última posibilidad, está claro que sólo agravando las penas por los delitos aquí tratados se conseguirá que los distintos candidatos - publicaciones o emisoras- se atengan a la verdad en sus informaciones generando en el elector confianza en el proceso electoral. Si se da prioridad al derecho a la libertad de expresión, nos retrotraemos a la primera doctrina del Tribunal Constitucional que en reiteradas ocasiones declaró la prevalencia de la misma, especialmente en materias de relevancia pública, y el proceso electoral lo es. No obstante, esta regulación está en consonancia con otros preceptos de la LOREG referidos a los delitos cometidos con motivo del proceso electoral, la finalidad de los cuales es la preservación de la transparencia del mismo. Teniendo en cuenta que ambos derechos se constituyen en la piedra basilar del Estado democrático de Derecho, creemos que resulta evidente que las particularidades de su regulación durante el proceso electoral están en la misma línea del resto del Capítulo VIII del Titulo I de la Ley electoral ${ }^{78}$.

\section{CONSIDERACIONES RESPECTO A LA POSIBILIDAD DE INTERPONER UN RECURSO DE AMPARO}

Sin ningún género de duda, aquél que se hubiera visto lesionado los derechos fundamentales que se intentan proteger a través de los recursos ordinarios articulados a tal efecto, con las particulares previsiones relativas al periodo electoral, puede interponer un recurso de amparo ante el Tribunal Constitucional por una posible vulneración del art. $18 \mathrm{CE}$, o alegando lesión del derecho reconocido en el art. 24.1 CE porque no ha sido restituido en vía ordinaria ${ }^{79}$. Por su parte, el responsable del medio que no publicó la rectificación o la publicó defectuosamente alegarà, en caso de recurrir la decisión del tribunal ordinario, que ésta vulnera el art. 20.d) ${ }^{80}$.

78 En contra M. J. Jiménez Díaz "Delitos electorales», en M. CoBo del Rosal (dir) Comentarios a la legislación penal, Madrid, 1994 pág. 76.

79 El primer caso, lo encontramos en el recurso que dio lugar a la STC 35/1983, y el segundo, por ejemplo, en la STC264/2988.

No compartimos, sin embargo, la fundamentación sugerida por el prof. $M$. CARRILlo, "Libertad de expresión...", op.cit.pág. 51, según el cual el derecho de rectificación, "como límite al derecho a la información (...) goza del mismo sistema de garantías que los demás (recurso ordinario y recurso de amparo constitucional".

80 Es el caso de la STC 168/1986. 
Ante la pregunta de si el Defensor del Pueblo podría interponer recurso de amparo, es claro que lo puede hacer en todo caso, por tanto, también cuando las informaciones afecten a los actores de los $\operatorname{comicios}^{81}$, aunque no tiene ninguna obligación de hacerlo.

En caso de presentar una demanda, el recurso se tramitaría por el procedimiento "ordinario" del recurso de amparo ${ }^{82}$, con lo que en caso de que los perjudicados hubiesen sido algún o algunos de los candidatos concurrentes, estos sólo podrían verse resarcidos de modo parcial pues el daño irrogado en su candidatura, o en la lista de candidatos en la que se halla incluido se habrían visto perjudicados en el momento de la votación. Y ello, porque todos sabemos que una información que desacredita a uno de los integrantes de una candidatura, al ser estas cerradas y bloqueadas, puede perjudicar las perspectivas de voto de todos los demás. Eso sin contar con que, seguramente, cuando el Tribunal fallase, el candidato en cuestión difícilmente podría remontar su debacle, por el tiempo transcurrido desde que ocurrieron los hechos.

\section{REFLEXIONES FINALES}

Con todo, a lo largo de la campaña electoral, la Ley ha previsto algunas medidas de protección encaminadas a que no puedan menoscabarse las posibilidades de obtener sufragios por parte de los candidatos concurrentes a causa de la difusión de informaciones que sean inexactas y puedan causarles dicho perjuicio, y también para que las informaciones que difundan los medios no contengan falsificaciones, ocultaciones...etc, que susceptibles de viciar las decisiones del Cuerpo Electoral.

Al respecto de una de ellas, estudiada en el presente trabajo y configurada en el art. 68 LOREG, no podemos finalizar nuestro análisis sin reparar en que, en relación con las actuaciones de Administración Electoral existen ciertos actos opacos cuando la información que se transmite a los posibles votantes no la elabora el medio, ${ }^{83}$ sino que, en

81 Art. 29 LO $3 / 1981$ y 46 de la LO 2/1979.

82 Recordemos que la Ley electoral (arts. 49.4 y 114.2) prevé dos procedimientos de "amparo electoral", cuya resolución se efectúa en un plazo máximo de tres y quince días respectivamente, pero que no resultan de aplicación al presente supuesto.

83 Como afirma el Alto Tribunal en su STC 41/1994, la actuación y la diligencia exigible al medio no puede ser equivalente cuando se trata de lo que se llama "una reportaje neutral" al transcribir las manifestaciones de otro, que la que 
particular, en la radio y televisión (pero también en la transcripción exacta de algunas declaraciones que aparecen en la prensa) en los informativos se retransmite en directo las declaraciones, mitines...,etc de algún candidato. En este caso, el medio cumple, con permanecer accesible a la persona o personas afectadas para que, a su vez puedan hacer públicas las alegaciones que estimen pertinentes mediante la rectificación de la anterior información ${ }^{84}$.

Sin embargo, hay situaciones como la conexión en directo con algunos actos de campaña electoral, en que los candidatos saben que sus palabras gozarán de gran audiencia, y el medio se limita a transmitir lo que está pasando, sin posibilidad de comprobar las afirmaciones vertidas, cuando todas las previsiones analizadas dejan de ser efectivas. Pues, aunque nada impide que puedan divulgarse las consiguiente rectificaciones, así como interponer las acciones pertinentes por lesiones al honor o por delitos de calumnia e injuria, consideramos que nada garantiza que los lectores o espectadores puedan conocer la falsedad de las informaciones o la comisión del delito de injuria o calumnia por parte de quien realizó los comentarios recogidos en los medios. A falta de esa información, la decisión soberana de orientación del sufragio podría verse afectada por la carencia de todos los datos que necesitarían.

se impone en la ordenación y presentación de hechos que el medio asume como propia. Así, "la exigencia del control de fundamento de la información proporcionada por sujetos externos provocaría una alteración de la función meramente informativa asumida por el medio , simplemente narrador de las declaraciones", "máxime cuando el contenido no supone la imputación de conductas desproporcionadamente graves». En el caso de un reportaje neutral, el deber de diligencia se cumple con "la constatación de la veracidad del hecho de la declaración", pero no "de la verdad de lo declarado". Ver SSTC 22/1995 y 52/1996.

No obstante, no podrá considerarse reportaje neutral cuando se le otorguen unas dimensiones informativas a través de las cuales el medio contradice de hecho la función de mero transmisor del mensaje. Así las SSTC 41/1994 y 52/1996.

También cabe la posibilidad de que el medio se limite a transmitir el contenido de un informe oficial. El tratarse de una transcripción resulta relevante a efectos de la valoración de la diligencia exigible sobre la veracidad de los hechos, pero no a los efectos de la rectificación de la noticia divulgada, que puede causar un descrédito a la persona a la que la información se refiere, pudiendo ésta, solicitar la rectificación o aclaración, completando la información proporcionada por el medio. Se admitiría pues el ejercicio del derecho de rectificación, sin que el mismo lesionara el derecho a transmitir información veraz, por cuanto los titulares o los comentarios que pueden preceder al informe son susceptibles de inducir a error al lector. Ver Sentencia de la Audiencia Provincial de Sevilla de 25 de marzo de 1993 y ATC 184/1994. 84 STC 41/1994. 